\title{
Prevalence of Children Witnessing Parental Violence
}

\author{
Tuyen D. Nguyen \\ California State University \\ PO Box 6868, Fullerton, California, USA \\ E-mail: Trunguyen@fullerton.edu \\ Susan Larsen \\ California State University \\ PO Box 6868 Fullerton, California, USA \\ E-mail: Slarsen@fullerton.edu
}

Received: December 13, 2011

Accepted: January 17, $2012 \quad$ Published: March 1, 2012

doi:10.5539/res.v4n1p148

URL: http://dx.doi.org/10.5539/res.v4n1p148

\begin{abstract}
This study examines the prevalence of children who witness domestic violence among their parents and the effects it has on their emotional health, specifically depression. A cross sectional survey design was used to identify the prevalence of children witnessing domestic violence in their homes. The study's sample contained 150 children collected among churches, schools, social organizations in the Dallas/Fort Worth area. The results showed that out of 150 sampled children, $32 \%(n=48)$ had witnessed parental violence in the previous year. Among the sampled participants who had witnessed at least one episode of parental abuse, $25 \%(\mathrm{n}=12)$ were identified as depressed as compared to $7 \%(\mathrm{n}=7)$ of children who did not witness parental abuse over the past year. Based on the results obtained from conducting this present study, recommendations are provided for both parents and clinicians.
\end{abstract}

Keywords: Children and parental violence, Effects on children and parental violence, Children witnessing parental violence, Effects on children and parental violence

\section{Introduction}

Domestic violence is increasingly demanding the attention of the courts, law enforcement, child protection, community services and society. Over 3.3 million children are at risk of exposure to parental violence each year (Carlson, 1994). Today, the criminal justice system responds to children witnessing domestic violence as a crime. However, even with this more conservative outlook on domestic violence/child abuse we continue to contend with the statistic that five children per day in the United States die at the hands of their parents and or caretakers (Crossen-Towers, 2004). As domestic violence continues to escalate in our society, there is a concurrent need for research on the cognitive, emotional and behavioral repercussions created by means of a child witnessing domestic violence in his or her home. Exposure constitutes seeing or hearing the actual abuse or suffering with the consequences of the aftermath of the abuse (Lemon, 1999).

Meichenbaum (1994) found that approximately, $45-70 \%$ of battered women in shelters reported the presence of children in the home during violence episodes. Children of all socio-economic classes, races, religions, ethnic backgrounds, and sexual orientations, witness and are therefore victims of domestic violence/child abuse each day in the United States. In the year 2004, there was an average of 5 child deaths per day in the United States, perpetrated by parents and or caregivers (Fantuzzo and Mohr, 1999). In view of the above statistics, a child witnessing domestic violence constitutes child abuse and is thus a social problem that is harmful to individuals, families, and society in a broad spectrum of ways.

Legally, the United States has made considerable advancements by creating a greater intolerance for domestic violence and child abuse nationwide. The now untimely ruling of 1868, in State v. Rhodes, the North Carolina Supreme Court which ruled that it would not, "interfere with family government in trifling cases" and on this 
ground affirmed the lower court's decision, which had held that, "the defendant had a right to whip his wife with a switch no larger than his thumb," is no longer a statement that can be rationalized legally, socially and or in terms of public policy. Contemporary state and federal laws such as: The Violence against Women Act and The Parental Kidnapping Prevention Act among others, have included provisions for the protection of women and children in domestic violence scenarios (Matthews, 2000 and Goelman, 2004).

\subsection{Defining domestic violence}

By definition, domestic violence includes not only physical abuse, yet emotional abuse, sexual abuse and abuse of property and pets as well (Ganley, 1989). Experiencing this type of violence whether the victim is a man, woman or child is potentially life-threatening by those offended and often leaves a victim with a sense of vulnerability, helplessness, defenselessness and hopelessness. When recounting the effects of domestic violence on children, it is important to observe that domestic violence and child abuse are most often present in the same families (Child Welfare Partnership, 1995). To analyze domestic violence thoroughly, it is prudent to break down the three sub-categories, as they are inter-connected parts that contribute to domestic violence as a whole.

\subsection{Emotional abuse}

Statistics confirm that the incidence of domestic violence as it relates to the emotional, physical and sexual violence in the lives of children is a serious public health problem. (i.e: Children from homes where domestic violence occurs are physically or sexually abused and/or seriously neglected at a rate 15 times that of the national average (McKay, 1994). Emotional abuse is a pattern of behavior that attacks a child's emotional development and sense of self-worth. Emotional abuse includes excessive, aggressive or unreasonable demands that place expectations on a child beyond his or her capacity. Persistent isolating, terrorizing, criticizing, belittling, insulting, rejecting and teasing are some of the forms these verbal attacks can take (Crossen-Towers, 2004). Emotional abuse also includes failure to provide the psychological nurturing necessary for a child's psychological growth and development -- providing no love, support or guidance (National Committee for the Prevention of Child Abuse, 1987).

\subsection{Physical abuse}

In a national survey of over 6,000 American families, it was estimated that between $53 \%$ and $70 \%$ of male batterers who assaulted their wives also habitually abused their children (Straus and Gelles, 1990). Other research suggests that women who have been battered by their husbands were twice as likely as other women to abuse a child (CWP, 1995). Findlater, J. and S. Kelly (1999) found evidenced that indicated that State agencies reported nearly 211,000 substantiated cases of child physical abuse and 128,000 cases of child sexual abuse, in homes where domestic violence was also known to exist.

By definition, physical abuse refers to any behavior that involves the intentional use of force against the body of another person that risks physical injury, harm, and/or pain (Dutton, 1992). Physical abuse includes pushing, hitting, slapping, choking, using an object to hit, twisting of a body part, forcing the ingestion of an unwanted substance, and use of a weapon (Crossen-Towers, 2004).

\subsection{Sexual abuse}

It has been estimated that about 1 in 3 female children and 1 in 6 male children may experience sexual molestation over the course of their life time (Regier and Cowdry, 1995). Children from homes where domestic violence occurs are physically or sexually abused and/or dangerously neglected at a rate 15 times the national average (McKay, 1994). Approximately, 45\% to 70\% of battered women in shelters have reported the presence of child abuse in their home (Meichenbaum, 1994). About two-thirds of abused children are being parented by battered women. Of the abused children, they are three times more likely to have been abused by their fathers (McKay, 1994).

Sexual abuse is defined as any unwanted sexual intimacy forced on one individual by another. It may include oral, anal, or vaginal stimulation or penetration, forced nudity, forced exposure to sexually explicit material or activity, or any other unwanted sexual activity (Dutton, 1994). Compliance may be obtained through actual or threatened physical force or through some other form of coercion.

\subsection{Symptoms of children who have witnessed repeated exposure to domestic violence}

The evidence is overwhelming that children who witness domestic violence do not escape unscathed (Carlson, 1984). However, researchers have found that children respond to domestic violence as uniquely, as their respective fingerprints. Attributes such as; average or above-average intellectual development, interpersonal skills, self-esteem, self-efficacy, attractiveness to others in both personality and appearance, individual talents, religious 
affiliations, socioeconomic advantage, good schooling and contact with people and environments that are positive, all assist in the probability of a more positive development outcome for children who witness domestic violence (Fantuzzo, 1999).

Domestic violence is often unanticipated and explosive. Repeated exposure to domestic violence creates extreme stress in children causing them to employ exceptional coping efforts. Witnessing domestic violence devastates a child's ability to feel protected and self-assured among many other problematic outcomes such as Post Tramatic Stress Disorder (PTSD) (Carlson, 1984).

Most Social Scientists, psychologists, law enforcement agents and academics concur that a child who witnesses domestic violence, even if never hit, is experiencing emotional trauma which causes indelible lifelong damage and therefore constitutes child abuse (see above section for list of observable and behavioral symptoms.) Many children develop PTSD (Post traumatic Stress Disorder), as a result of repeated exposure to domestic violence. Often children, who obtain PTSD via witnessing domestic violence, begin to perseverate about the violence, thereby creating an overall disturbance in their daily and long-term functioning. Graham-Bermann (1994) found that more than half of the school-age children in domestic violence shelters show clinical levels of anxiety or posttraumatic stress disorder. Such children, without treatment, are at significant risk for delinquency, substance abuse, school drop-out, and difficulties as well as lifelong interpersonal difficulties.

According to the Diagnostic and Statistical Manual of Mental Disorders (DSM-IV; APA, 1994) for an individual to be diagnosed with posttraumatic stress disorder, he or she must have experienced or witnessed a life-threatening event and reacted with intense fear, helplessness, or horror. The traumatic

event is persistently reexperienced (e.g., distressing recollections), there is persistent avoidance of stimuli associated with the trauma, and the victim experiences some form of hyper arousal (e.g., exaggerated startle response). These symptoms persist for more than one month and cause clinically significant impairment in daily functioning. When the disturbance lasts a minimum of two days and as long as four weeks from the traumatic event, Acute Stress Disorder may be a more accurate diagnosis (DSM-IV; APA, 1994). Most children who witness ongoing domestic violence meet many if not all of the above criteria.

Numerous studies have documented multiple problems among children that are significantly associated with a child's witnessing assaults of one parent by another in the home (Lemon, 1999., Groves, 1999., Mathews, 2000., Wolfe, 1999.) These problems include short and long-term repercussions such as:

Psychological and emotional problems such as depression, hostility, anxiety, social withdrawal. Agitation, aggression, avoidance of reminders, behavior problems, clinginess to caregivers, distractibility, emotional numbing, emotional changes, flashbacks, general emotional distress, increased arousal, intrusive thoughts, insomnia, and irritability.

Cognitive functioning problems such as academic problems, lower verbal and quantitative skills and the development of attitudes of solving problems via violence.

Longer-term development problems such as depression, trauma-related symptoms and low self-esteem among women and trauma-related symptoms alone among men. In addition, low levels of empathy low self-esteem; nightmares; numbing of feelings; obsessive behaviors; phobias; poor problem-solving skills; posttraumatic stress disorder; revenge seeking etc.

The psychological and emotional problems, the cognitive functioning problems and or the longer-term developmental problems are all magnified or decreased by a number of mitigating factors including: whether or not the child has also been a victim of physical, sexual abuse and or neglect, a child's age and gender at the time that he/she witnessed the domestic violence, the amount of time that has passed since witnessing violence, where the child is living (i.e. is the perpetrators presence still a threat (perceived or otherwise) to the child). Fantuzzo and Mohr, (1999) Carter, Weithorn and Behrman (1999) have all made deductions and distinctions about the various stages of child development as a means of explaining the innumerable symptoms related to domestic violence exposure. These stages of child development and a demarcation of their respective symptoms are listed below:

\subsection{Infants and toddlers}

Infants and toddlers who witness violence show severe irritability, undeveloped behavior, sleep disturbances, emotional anguish, fears of being alone, and regression in toileting and language. Preschool children may develop enuresis and speech deficiencies. Witnessing domestic violence during the infant-toddler stage, interferes with a child's typical development of trust and later exploratory behaviors, which lead to the development of autonomy (Carter, Weithorn and Behrman, 1999). 


\subsection{Pre-adolescents}

The pre-adolescent child classically has a greater capacity to externalize negative emotions (i.e., to verbalize). In addition to symptoms frequently seen with childhood anxiety (e.g., sleep problems, eating disturbance, nightmares), victims within this age group may show a shortfall of interest in social activities, low self-concept, isolation or avoidance of peer relations, rebelliousness and oppositional-defiant behavior in the school setting. It is also typical to observe temper tantrums, irritability, frequent fighting at school or between siblings, lashing out at objects, treating pets cruelly or abusively, threatening of peers or siblings with violence, and attempts to gain attention through hitting, kicking, or choking peers and/or family members(Carter, Weithorn and Behrman, 1999).

\subsection{Teens}

Teens entrenched in a home where domestic violence exists confront the problem of trying to blend in with their peers while keeping their home life undisclosed. The outcome can be teens that on no account learn to form trusting, lasting relationships, or teens who end up in violent relationships themselves (either as the perpetrator most often in the case of males and or the victim more often in the case of female teens who witness domestic violence in the home.).

Additionally, teens face the same issues as younger children in an abusive family that is feeling lonely and isolated, parentification, behavior tribulations, stress related medical and mental health problems, and difficulties in school. Teenagers who grow up in violence homes are more likely to engage in drug and alcohol abuse, smoking, risky sexual behavior, and aggressive, anti-social behavior (Goldman, Horan, Warshaw, Kaplan and Hendricks-Matthews, 1995).

\section{Method}

A cross sectional survey design was used to identify the prevalence of children witnessing domestic violence in their homes. The sample of 150 children residing in the Dallas/Fort Worth area was collected. After securing the approval of parents, the first author attended churches, schools, and

social organizations in the Dallas/Fort Worth area to recruit participants for the study.

\subsection{Study's participants}

Participants were 150 children, 80 girls and 70 boys from the Dallas/Fort Worth, Texas metropolitan area with the mean age of 8.4 years. As a group, $60 \%$ of these children's parents had a high school education, $25 \%$ had less than a high school education, and the remaining had attended or completed a university education. The participants' family annual incomes range from $\$ 25678$ to $\$ 78965$ with a median income of $\$ 45867$.

\subsection{Research questions}

This present study was driven by two main research questions:

1) What is the prevalence of children witnessing parental violence?

2) Is there a significant difference between the sampled children who witness parental violence versus their counterparts who do not, with respect to their depression levels?

\subsection{Measure}

Research Questionnaire: This questionnaire was developed for the purposes of this study to gather information on sociodemographic variables including age, family annual income, depression, and frequency of witnessing parental abuse. The instrument utilized in this study deemed to contain content validity as evidenced by the questions consisted in the questionnaire. The instrument consists of seven questions that measure the presence of witnessing of parental physical abuse, verbal abuse, and sexual abuse. For the depression subscale, there are sixteen questions employed to measure the construct. The Cronbach's alpha coefficients for the parental violence and depression subscales were 0.78 and .71 , respectively.

\subsection{Procedure}

The data collection took three months to complete. The first author recruited the study's participants from various churches, schools, and social organizations in the Dallas/Fort Worth metropolitan area. Once the study's participants had agreed to allow their children to participate in the present study, informed consent was obtained. The parents were assured that the results would be used for educational purposes and their children's identities would remain anonymous and confidential. The parents were present when the study's participants completed the instrument for this study. The participants were asked of their family's annual income. For children who were too young to complete the instrument on their own, the parents read the questions to them. The whole instrument took an average of twenty minutes to complete. 


\section{Results}

\subsection{Sample}

A total of 150 children were drawn from churches, schools, and social organizations in the Dallas/Fort Worth area participated in the research. The average age of the total sample ranged from 5 years old to 15 years old with a mean of 8.4 years.

\subsection{Prevalence of children witnessing parental violence}

Among the sampled participants, $32 \%(\mathrm{n}=48)$ were identified as having witnessed parental abuse at least once in the previous year and $68 \%(\mathrm{n}=102)$ reported as not having witnessed parental abuse in the previous year.

\subsection{Prevalence of depression}

Among the sampled participants who had witnessed at least one episode of parental abuse, $25 \%(n=12)$ were identified as depressed as compared to $7 \%(\mathrm{n}=7)$ of children who did not witness parental abuse over the past year.

\section{Discussion}

Studies (Culross, 1999; Fantuzzo and Mohr, 1999) have shown children who regularly witness abuse between their fathers and mothers exhibit post-traumatic stress symptoms, similar to those acquired by soldiers in combat. Compared to their counterparts, children from abusive homes as a whole are less spontaneous in their behavior and play; they are more preoccupied, withdrawn, irritable, or act out their anger. The present study shows that $35 \%$ of the sampled participants have witnessed parental violence, which mirrors the prevalence of intimate partner abuse in the United States (Pampel and Williams, 2000). The present study also indicates that there is a difference in depression level between children who witness parental violence and their counterparts who don't witness such an event in their lives. The study's results have real implications for both parents and clinicians in the helping profession who work with children in a clinical setting.

\subsection{Recommendations for parents}

Parents should realize that the home environment is a training ground for children regarding intimate relationships. Realize that children's mental health is impacted by the parental violence that goes on in the home, especially with their depression level as evidenced by the results of the present study. Know what relationship lessons are being taught to children on a daily basis. The examples that one sets for children today will be repeated in their own lives tomorrow. A parent's actions today, to a great extent, influence either directly or indirectly their children's future family quality. However, never be afraid to let one's children witness appropriate ways that parents handle conflicts and differences among themselves.

Families should have weekly or bi-weekly meetings in which all members are encouraged to voice their concerns as well as their successes in their lives. During these family meetings, children are encouraged to express their emotions, especially after parental confrontational incidents. Other purposes of family meetings are to prevent any anger build-ups that may be taking place as well and to build a sense of community with open communication in the home. For families in which domestic violence has been a long tradition, professional help is called for.

\subsection{Recommendations for clinicians}

Establishing strong rapport with children clients from abusive homes is utmost important early on in the therapeutic relationship. Be extremely patient with these children as they begin to open up about the abuse they have witnessed in their own homes; honor their resistance if they choose not to share for the time being. Building rapport and trust with the children should be a primary treatment goal above everything else. Clinicians should pay special attention to the prevalence of depression among children who come from abusive homes and to assess them appropriately for the purposes of treatment.

To encourage children in sharing of domestic violence incidents which they have witnessed, play therapy may be used by the clinician. Provide the children with "security" toys as they work on their family's domestic violence issues in sessions. Clinicians need to be aware of the possibility of re-traumatization as the children re-live traumatic events through sharing. Know when to re-focus the session to a lighter topic, as communicated by the children's verbal and non-verbal body language.

Putting children in therapy groups with other children is essentially helpful for them so they can relate to others with similar experiences. In group children will learn that domestic violence does not happen to them alone, but to others as well. Children's groups normally consist of 5-6 members with more or less same age and development. In a group setting, the children's experiences with witnessing parental violence as well as their depression can be addressed by the clinician in a safe and supportive environment. 


\section{References}

American Psychiatric Association. (1994). Diagnostic and statistical manual of mental disorders (4th Ed.). Washington, DC: Author.

American Psychological Association Presidential Task Force on Violence and the Family. Issues and Dilemmas in Family Violence: Executive Summary. American Psychological Association Web Site.

Carlson, B. E. (1984). Children's observations of interpersonal violence. In A. R. Edwards (Ed.), Battered women and their families, 147-167. New York: Springer.

Carter, L., Weithorn, L. \& Behrman, R. (1999). Domestic violence and children: Analysis and recommendations. The Future of Children: Domestic Violence and Children, 9(3), 1-20.

Child Welfare Partnership. (1995). Domestic violence summary: The intersection of child abuse and domestic violence. Published by Portland State University.

Culross, P. (1999). Health care system responses to children exposed to domestic violence. The Future of Children: Domestic Violence and Children, 9(3), 111-121.

Dutton, M. A. (1992). Women's response to battering: Assessment and intervention. New York: Springer.

Dutton, M. A. (1994). Post-traumatic therapy with domestic violence survivors. In M.B. Williams and J.F. Sommer (Eds.), Handbook of post-traumatic therapy, 146-161. Westport, CT: Greenwood Press.

Fantuzzo, J. \& Mohr, W. (1999). Prevalence and effects of child exposure to domestic violence. The Future of Children: Domestic Violence and Children, 9(3), 21-32.

Findlater, J. \& Kelly, S. (1999). Child protective services and domestic violence. The Future of Children: Domestic Violence and Children, 9(3), 84-98.

Foy, D. W. (1992). Introduction and description of the disorder. In D. W. Foy (Ed.), Treating PTSD: Cognitive-Behavioral strategies, 1-12. New York: Guilford.

Ganley, A. (1989). Integrating feminist and social learning analyses of aggression: Creating multiple models for intervention with men who battered. In P. Caesar and L. Hamberger (Eds.), Treating men who batter, 196-235. New York: Springer.

Graham-Bermann, S. (1994). Preventing domestic violence. University of Michigan research information index. UM-Research-WEB@umich.edu.

Groves, B. (1999). Mental health services for children who witness domestic violence. The Future of Children: Domestic Violence and Children, 9(3), 122-132.

Heise, L., Ellsberg, M. \& Gottemoeller. M. (1999). Ending violence against women. Population Reports, Series L, No. 11. Baltimore, Johns Hopkins University School of Public Health, Population Information Program.

Lemon, N. (1999). The legal system's response to children exposed to domestic violence. The Future of Children: Domestic Violence and Children, 9(3), 67-83.

Matthews, M. (2000). The impact of federal and state laws on children exposed to domestic violence. The Future of Children: Domestic Violence and Children, 9(3), 50-66.

McKay, M. (1994). The link between domestic violence and child abuse: Assessment and treatment considerations. Child Welfare League of America, 73, 29-39.

Meichenbaum, D. (1994). A clinical handbook/practical therapist manual for assessing and treating adults with post-traumatic stress disorder. Ontario, Canada: Institute Press.

Osofsky, J. (1999). The impact of violence on children. The Future of Children: Domestic Violence and Children, 9(3), 33-49.

Pampel, F. \& Williams, K. (2000). Intimacy and homicide: Compensating for missing data in the SHR, 38 (2), 661-680.

Programs, Bureau of Justice Statistics. (2000). NCJ 178247, Revised 7/14/00.

Regier, D. A. \& Cowdry, R. W. (1995). Research on violence and traumatic stress (program announcement, PA 95-068). National Institute of Mental Health.

Rennison, M. \& Welchans, W. Intimate Partner Violence. U.S. Department of Justice, Office of Justice.

Rodriguez, M., Bauer, H., McLoughlin, E. \& Grumbach, K. (1999). Screening and intervention for intimate 
partner abuse: Practices and attitudes of primary care physicians. JAMA, The Journal of the American Medical Association, 282, 468-474. http://dx.doi.org/10.1001/jama.282.5.468

Straus, M. A. \& Gelles, R. J. (1990). Physical violence in American families. New Brunswick, NJ: Transaction Publishers.

Terr, L. (1991). Childhood trauma: An outline and overview. American Journal of Psychiatry, 148, 10-20.

Wolfe, D. \& Jaffe, P. (1999). Emerging strategies in the prevention of domestic violence. The Future of Children: Domestic Violence and Children, 9(3), 133-144.

Table 1. Prevalence of children witnessing parental violence

\begin{tabular}{ccc}
\hline Variable & $\mathrm{N}$ & Percentage $\%$ \\
\hline Prevalence & 150 & $100 \%$ \\
Witness & 48 & $32 \%$ \\
Non-Witness & 102 & $68 \%$ \\
\hline
\end{tabular}

Table 2. Depression prevalence

\begin{tabular}{ccc}
\hline Variable & $\mathrm{N}$ & Percentage $\%$ \\
\hline Depression Prevalence & 19 & $100 \%$ \\
Depressed & 12 & $25 \%$ \\
Non-Depressed & 7 & $7 \%$ \\
\hline
\end{tabular}

